\title{
JOINT SELECTION FOR BOTH EXTREMES OF MEAN PERFORMANCE AND OF SENSITIVITY TO A MACROENVIRONMENTAL VARIABLE
}

\section{GROWTH PATTERN AND SENSITIVITY}

\author{
HILARIE BOUGHEY, J. L. JINKS, D. COOMBS and W. SHUFFLEBOTHAM \\ Department of Genetics, University of Birmingham, Birmingham B15 2TT
}

Received 18.iv.78

\section{SUMMARY}

\begin{abstract}
A relationship is demonstrated between pattern of growth, as summarised by either the quadratic coefficient of the growth curve or the proportion of the final height achieved by the middle of the growing season, and environmental sensitivity of final height among the $60 \mathrm{D}$ inbred lines derived from a cross between varieties 2 and 12 of Nicotiana rustica.

The heritability and repeatability over diverse environments of the quadratic coefficient are both relatively high. Indirect selection for environmental sensitivity by selecting for the quadratic coefficient is, therefore, a practical alternative that overcomes many of the problems of direct selection reported by Brumpton, Boughey and Jinks (1977) and Jinks; Jayasekara and Boughey (1977).
\end{abstract}

\section{INTRODUCTION}

BoUGHEY AND JINKS (1978) provided further evidence that pattern of growth in Nicotiana rustica is a major determinant of environmental sensitivity for final height (see earlier reports in Perkins and Jinks, 1968 and Perkins, 1974). They showed that the proportion of final height or height at flowering time achieved by the sixth week of growth in the field accounted for more of the differences in environmental sensitivity among 60 inbred lines, derived by single seed descent from the cross between varieties 2 and 12, than any other of their properties measured at that time.

Growth curves have now been obtained for each of these 60 inbreds (D lines) and these have been examined for further evidence of this relationship.

\section{Material}

Eight individually randomised siblings of the $\mathrm{F}_{9}$ families of the $60 \mathrm{D}$ inbred lines were grown at the Edgbaston site in 1977 as part of a larger experiment. The latter also included a sample of 480 individually randomised plants of the $F_{2}$ from which the $D$ lines were derived by single seed descent. Among the $\mathrm{D}$ lines were the four $\mathrm{FH}$ selections made in 1972 for the four combinations of high $(H)$ and low $(L)$ mean performance and high $(h)$ and low $(l)$ sensitivity to eight environmental treatments consisting of two planting densities at each of four sowing dates.

The height of each of the 960 plants $\left(F_{2}\right.$ and $\left.F_{9}\right)$ was measured in millimetres at weekly intervals starting two weeks after planting in the field 
(H1) until growth ceased $(F H)$. A maximum of fifteen measurements were made on any one plant ( $H 1$ to $H 15)$.

\section{Analysis}

Previously we showed that the proportion of a plant's final height achieved approximately half way through the growing season (6 weeks after planting in the field) was more highly correlated with environmental sensitivity than any other property measured at that time. Statistics which measure the rate at which a plant achieves its maximum rate of growth and to a lesser extent the rate at which all growth ceases are, therefore, more likely to be correlated with environmental sensitivity than, for example, rate of growth itself. The higher order (quadratic, cubic, etc.) components of the growth curves are, therefore, more likely to be correlated with environmental sensitivity than the linear component. Although the variances of the height measurements increased as height increased with time, thus making any unweighted regression analysis unreliable, a quick check on these expectations and on the shapes of the growth curves were obtained by carrying out an.'. '. omial regression of height on time (in weeks) for each of the 960 plants. Because some plants ceased growth as early as the eighth weekly measurement and a few as late as the fifteenth, two analyses were carried out. The first was based on the first 10 weekly measurements $(H 1$ to $H 10)$ for every plant, this being the average time taken to reach their final height. The second was based on the number of measurements taken before each plant individually reached its final height which varied from eight to fifteen.

These preliminary analyses showed that a growth curve which included significant linear, quadratic and cubic components was adequate for every plant in that it failed to account for all the significant changes in height no more often than would be expected by random chance alone. As expected, the quadratic and cubic components, but not the linear components, were significantly correlated with the values of the environmental sensitivities of the D lines obtained in 1972 (Jinks, Jayasekara and Boughey, 1977; Boughey and Jinks, 1978). Of the two sets of data analysed, that consisting of the first 10 measurements for every plant was the more satisfactory; it gave significantly greater discrimination between the $60 \mathrm{D}$ lines and significantly greater correlations with their environmental sensitivities. It was decided, therefore, to proceed with a weighted regression analysis of the first ten measurements of each plant using as weights the reciprocal of the error variance of each height measurement obtained from the replicate differences within each family.

The causes of the variation in the components of the growth curves can be analysed as follows. If we assume that an additive-dominance genetic and additive environmental model is adequate (Mather and Jinks, 1971) the expected means and variances or variance components of the $F_{2}$ and of the random inbred lines derived from it $\left(F_{\infty}\right)$ for a completely randomised experiment are

$$
\begin{aligned}
& \bar{F}_{2}=m+\frac{1}{2}[h] \quad V_{1 F_{2}}=\frac{1}{2} D+\frac{1}{4} H+E_{1} \\
& \bar{F}_{\infty}=m \quad \sigma_{b F_{\infty}}^{2}=D \quad \sigma_{w F_{\infty}}^{2}=E_{1}
\end{aligned}
$$


TABLe 1

Estimates of the linear, quadratic and cubic regression coefficients from weighted regression analyses of the growth curves of the $60 \mathrm{D}$ lines and of their environmental sensitivities

\begin{tabular}{|c|c|c|c|c|}
\hline \multirow[b]{2}{*}{ D line } & \multicolumn{3}{|c|}{ Regression coefficients } & \multirow{2}{*}{$\begin{array}{c}\text { Environmental } \\
\text { sensitivity }\end{array}$} \\
\hline & Linear & Quadratic & Cubic & \\
\hline 1 & $140 \cdot 32$ & $-4 \cdot 74$ & $-3 \cdot 26$ & $4 \cdot 63$ \\
\hline 2 & 192.49 & $-2 \cdot 23$ & $-4 \cdot 54$ & $5 \cdot 51$ \\
\hline 3 & $98 \cdot 32$ & $21 \cdot 96$ & $I \cdot 60$ & $9 \cdot 86$ \\
\hline 4 & 80.97 & 7.65 & -0.42 & $6 \cdot 50$ \\
\hline 5 & $129 \cdot 98$ & $4 \cdot 37$ & $-2 \cdot 02$ & $10 \cdot 65$ \\
\hline 6 & $196 \cdot 30$ & 8.63 & $-2 \cdot 60$ & 10.69 \\
\hline 7 & $174 \cdot 26$ & $8 \cdot 71$ & $-2 \cdot 30$ & 8.98 \\
\hline 8 & $177 \cdot 42$ & $18 \cdot 65$ & -0.66 & $9 \cdot 50$ \\
\hline 9 & $183 \cdot 61$ & $-2 \cdot 21$ & $-4 \cdot 04$ & $3 \cdot 27$ \\
\hline 10 & $135 \cdot 18$ & -6.55 & -3.02 & $1 \cdot 16$ \\
\hline 11 & $209 \cdot 86$ & 3.97 & $-3 \cdot 90$ & $8 \cdot 15$ \\
\hline 12 & $171 \cdot 30$ & $-6 \cdot 85$ & $-4 \cdot 18$ & $9 \cdot 28$ \\
\hline 13 & $106 \cdot 09$ & $15 \cdot 26$ & $0 \cdot 24$ & $8 \cdot 21$ \\
\hline 14 & $170 \cdot 62$ & $-2 \cdot 07$ & -3.95 & $8 \cdot 45$ \\
\hline 15 & $174 \cdot 29$ & $10 \cdot 30$ & $-2 \cdot 24$ & $10 \cdot 47$ \\
\hline 16 & $187 \cdot 61$ & $-2 \cdot 10$ & $-4 \cdot 15$ & 6.53 \\
\hline 17 & 174.98 & $20 \cdot 34$ & -0.19 & $10 \cdot 21$ \\
\hline 18 & $127 \cdot 80$ & 10.63 & $-1 \cdot 00$ & 5.46 \\
\hline 19 & 178.26 & -5.66 & -3.93 & $7 \cdot 44$ \\
\hline 20 & $191 \cdot 94$ & $-5 \cdot 54$ & $-4 \cdot 42$ & $7 \cdot 42$ \\
\hline 21 & $151 \cdot 34$ & 12.68 & $-1 \cdot 03$ & $12 \cdot 83$ \\
\hline 22 & $191 \cdot 97$ & -7.26 & $-4 \cdot 57$ & $6 \cdot 62$ \\
\hline 23 & 99.47 & $15 \cdot 80$ & 0.58 & 10.65 \\
\hline 24 & $155 \cdot 16$ & $-4 \cdot 48$ & -3.47 & $6 \cdot 20$ \\
\hline 25 & $246 \cdot 66$ & $-6 \cdot 74$ & $-6 \cdot 03$ & $8 \cdot 02$ \\
\hline 26 & 87.23 & $12 \cdot 93$ & 0.34 & $12 \cdot 27$ \\
\hline 27 & $149 \cdot 02$ & 9.69 & -1.48 & $10 \cdot 10$ \\
\hline 28 & 155.44 & $5 \cdot 36$ & -2.27 & $5 \cdot 60$ \\
\hline 29 & 239.54 & $-2 \cdot 39$ & -5.21 & $7 \cdot 76$ \\
\hline 30 & $206 \cdot 54$ & -0.72 & $-4 \cdot 22$ & 9.55 \\
\hline 31 & $159 \cdot 64$ & $-4 \cdot 13$ & $-3 \cdot 73$ & $5 \cdot 77$ \\
\hline 32 & 163.96 & $4 \cdot 78$ & $-2 \cdot 71$ & 8.90 \\
\hline 33 & 228.48 & $1 \cdot 60$ & $-4 \cdot 11$ & $10 \cdot 27$ \\
\hline 34 & 122.97 & $3 \cdot 48$ & -1.98 & 4.55 \\
\hline 35 & 63.65 & $8 \cdot 73$ & 0.18 & $6 \cdot 16$ \\
\hline 36 & $170 \cdot 49$ & $3 \cdot 63$ & -2.98 & $4 \cdot 33$ \\
\hline 37 & $170 \cdot 17$ & -2.92 & $-4 \cdot 21$ & $8 \cdot 76$ \\
\hline 38 & 135.80 & $15 \cdot 14$ & -0.44 & 8.04 \\
\hline 39 & 165.98 & $8 \cdot 43$ & -2.19 & $6 \cdot 35$ \\
\hline 40 & 155.95 & $3 \cdot 89$ & -2.61 & $6 \cdot 28$ \\
\hline 41 & 178.76 & $-1 \cdot 31$ & -4.09 & $6 \cdot 24$ \\
\hline 42 & $164 \cdot 50$ & $-6 \cdot 43$ & -4.06 & $5 \cdot 42$ \\
\hline 43 & 140.17 & $13 \cdot 31$ & -0.86 & $7 \cdot 29$ \\
\hline 44 & 191.58 & $-1 \cdot 44$ & $-4 \cdot 33$ & 3.21 \\
\hline 45 & $160 \cdot 13$ & 6.89 & $-2 \cdot 28$ & 8.44 \\
\hline 46 & $137 \cdot 91$ & $3 \cdot 77$ & $-2 \cdot 31$ & - \\
\hline 47 & 135.17 & $8 \cdot 67$ & -1.58 & $7 \cdot 71$ \\
\hline 48 & $171 \cdot 36$ & $1 \cdot 80$ & $-3 \cdot 40$ & $7 \cdot 42$ \\
\hline 49 & 203.04 & $-2 \cdot 60$ & -4.41 & 4.25 \\
\hline 50 & $231 \cdot 37$ & $-6 \cdot 90$ & $-5 \cdot 62$ & $11 \cdot 64$ \\
\hline 51 & $212 \cdot 13$ & -5.89 & $-5 \cdot 10$ & 8.40 \\
\hline 52 & 123.89 & $6 \cdot 26$ & -1.45 & $8 \cdot 85$ \\
\hline 53 & 118.01 & 12.55 & -0.40 & $8 \cdot 66$ \\
\hline 54 & $127 \cdot 41$ & 11.39 & -0.77 & 7.56 \\
\hline 55 & $232 \cdot 27$ & $2 \cdot 06$ & -4.89 & $10 \cdot 50$ \\
\hline 56 & $191 \cdot 82$ & $0 \cdot 14$ & -4.08 & $5 \cdot 22$ \\
\hline 57 & $174 \cdot 26$ & $12 \cdot 24$ & -2.09 & $4 \cdot 55$ \\
\hline 58 & $157 \cdot 67$ & 5.91 & -2.57 & $6 \cdot 75$ \\
\hline 59 & 139.54 & 7.67 & $-1 \cdot 60$ & 7.51 \\
\hline 60 & 131.59 & $16 \cdot 30$ & -0.26 & 10.44 \\
\hline ine mean & $162 \cdot 39$ & $4 \cdot 24$ & $-2 \cdot 62$ & $7 \cdot 65$ \\
\hline
\end{tabular}


from which we can estimate the additive $(D)$, dominance $(H)$ and environmental $\left(E_{1}\right)$ components of variation, any net directional dominance $([h])$ and the narrow heritability. Even if, however, this simple model is inadequate, $\frac{1}{2} \sigma^{2}{ }_{b F_{\infty}} / V_{1 F_{2}}$ estimates the proportion of fixable variation in the $\mathrm{F}_{2}$, which is the narrow heritability, and $2\left(\bar{F}_{2}-\bar{F}_{\infty}\right)$ measures net directional non-additivity.

\section{Results}

In table 1 are listed the weighted least squares estimates of the linear, quadratic and cubic regression coefficients from analyses of the 480 plants of the $60 \mathrm{D}$ lines averaged over replicate plants within lines. In the last column are given the 1972 estimates of their environmental sensitivities. There is no estimate of the latter for line 46, so it cannot, therefore, be included in any subsequent analysis involving these estimates.

Analyses of variance of the linear; quadratic and cubic regression coefficients, in which the 480 estimates of each coefficient are partitioned into differences between the 60 lines for 59 degrees of freedom and the differences between the eight individuals within each line pooled over all lines for 420 degrees of freedom $(60 \times 7)$, are summarised in table 2. There are

\section{TABLE 2}

Analyses of variance of the linear, quadratic and cubic regression coefficients of the growth curces of the $60 \mathrm{D}$ lines

\begin{tabular}{|c|c|c|c|c|}
\hline $\begin{array}{l}\text { Regression } \\
\text { component }\end{array}$ & Item & d.f. & M.S. & VR \\
\hline \multirow[t]{2}{*}{ Linear } & Between lines & 59 & 123.595 & $26 \cdot 5 * * *$ \\
\hline & Within lines & 420 & 4.667 & \\
\hline \multirow[t]{2}{*}{ Quadratic } & Between lines & 59 & 4.932 & $38.9 * * *$ \\
\hline & Within lines & 420 & 0.127 & \\
\hline \multirow[t]{2}{*}{ Cubic } & Between lines & 59 & 0.251 & $45 \cdot 6 * * *$ \\
\hline & Within lines & 420 & 0.006 & \\
\hline
\end{tabular}

highly significant differences between lines for all three of the significant components of their growth curves and, as we shall see later, this implies substantial additive genetic control of these differences.

In table 3 we present the correlations between the 59 estimates of each of the linear, quadratic and cubic regression coefficients and of the environmental sensitivities listed in table 1. With the exception of the correlation

TABLE 3

Correlations between the linear, quadratic and cubic regression coefficients and environmental sensitivity among 59 of the $D$ lines

$\begin{array}{lccc}\text { Component } & \text { Quadratic } & \text { Cubic } & \begin{array}{c}\text { Environmental } \\ \text { sensitivity }\end{array} \\ \text { Linear } & 0.55 * * * & -0.85 * * * & 0.01 \text { NS } \\ \text { Quadratic } & - & 0.90 * * * & 0.41 * * * \\ \text { Cubic } & - & - & 0.26 * \\ & \text { NS } & =P>0.05 & \\ * & =P=0.05-0.01 \\ * * * & =P<0.001\end{array}$




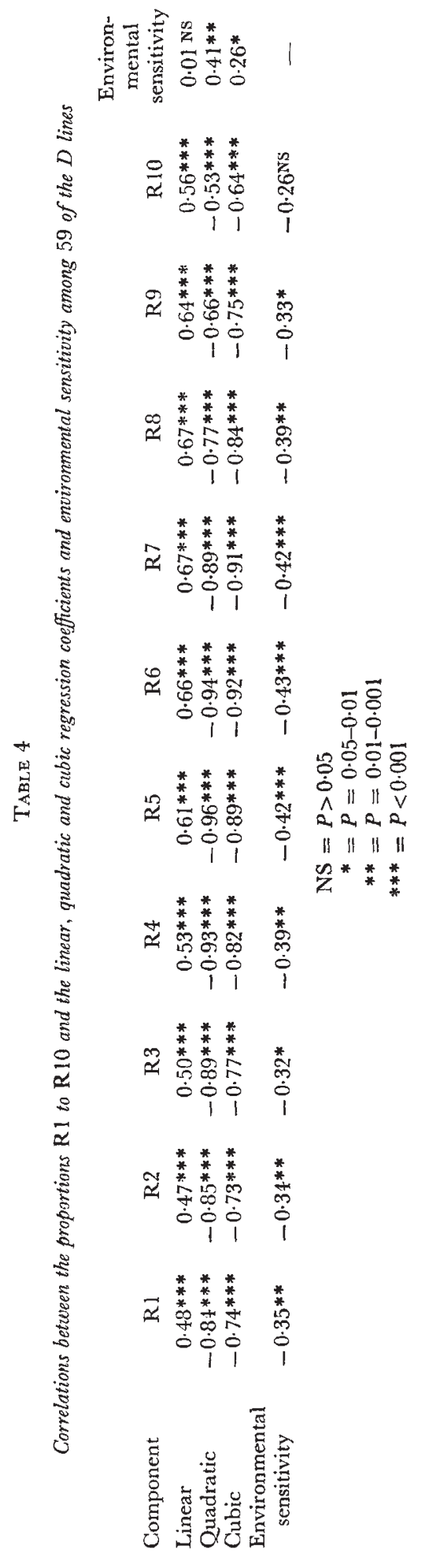


between the linear regression coefficients and environmental sensitivity, all are significant $(P \leqq 0 \cdot 05)$. Thus the estimates of the linear, quadratic and cubic components of the growth curves are not independent and the correlations between the quadratic component, and to a lesser extent the cubic component, and environmental sensitivity are confirmed.

Our data not only allow us to re-examine the relationship we reported (Boughey and Jinks, 1978) between the proportion of the final height achieved by the sixth week after planting and environmental sensitivity, but also to extend the comparisons to include all the proportions from one to ten weeks after planting. The correlations between these proportions (labelled Rl to R10) and environmental sensitivity over the 59 lines are given in table 4. With the exception of that with R10, all the correlations are significant; but the largest correlations fall between R5 and R7, R5 being the nearest equivalent to the sixth week after planting in 1975. Indeed the correlations involving R5 to R7 are as high as those observed for the

\section{TABLE 5}

Narrow heritabilities of the linear, quadratic and cubic regression coefficients, $R 5$ and a sample of other characters which show the range of values found in this material

$\begin{array}{lc}\text { Character } & \text { Narrow heritability } \\ \text { Growth rate } & \\ \text { Linear component } & 0.51 \pm 0.10 \\ \text { Quadratic component } & 0.58 \pm 0.12 \\ \text { Cubic component } & 0.63 \pm 0.13 \\ \text { Height at 2 weeks } & 0.45 \pm 0.09 \\ \text { Final height } & 0.40 \pm 0.08 \\ \text { Flowering time } & 0.68 \pm 0.13 \\ \text { Leaf length } & 0.22 \pm 0.05 \\ \text { R5 } & 0.54 \pm 0.11\end{array}$

quadratic component of the growth curves, although not as high as that observed for the sixth week after planting in 1975 (Boughey and Jinks, 1978). The reason for the close agreement between these proportions and the quadratic component of the growth curves becomes apparent when we calculate the correlations between the proportions R1 to R 10 and the linear, quadratic and cubic regression coefficients (table 4). All of these correlations are significant but by far the highest correlations are obtained between the quadratic coefficients and the ratios $\mathrm{Rl}$ to $\mathrm{R} 7$. In fact, the ratio between the quadratic coefficients and $\mathrm{R} 5$ reaches the remarkably high value of -0.96 . Clearly, the informational content of R5 and of the quadratic coefficients are virtually identical and as predictors of environmental sensitivity they are indistinguishable.

One objective in investigating these correlations is the prospect of selecting for environmental sensitivity indirectly, thereby avoiding the difficulties which were encountered during direct selection (Brumpton, Boughey and Jinks, 1977; Jinks, Jayasekara and Boughey, 1977). Selection based on either the quadratic regression coefficient or R 5 would be equally satisfactory alternatives for this purpose. Furthermore, both have narrow heritabilities which are at the higher end of the range observed in the $F_{2}$ of the cross between varieties 2 and 12 (table 5). The use of either would remove the necessity of observing the final height of each genotype in a 
number of environments. But since the quadratic regression coefficient and R5 cannot be estimated until many or all plants, respectively, have ceased growth, their use would not remove the necessity for using family selection and therefore having to raise a second sample of each of the selected families for breeding purposes (see Brumpton, Boughey and Jinks, 1977). This could be avoided only if the individuals or families we wish to select could be identified earlier in the season. To investigate this possibility we have

TABLE 6

The narrow heritabilities of the quadratic regression coefficients of growth rate obtained by fitting cubic regressions to the first 4, 5, 6, 7, 8, 9 and 10 height measurements and the correlations between these quadratic coefficients and environmental sensitivity in the $59 \mathrm{D}$ lines

$\begin{array}{ccc}\text { Number of heights } & \text { Heritability } & \text { Correlation } \\ 4 & 0.38 & -0.28^{*} \\ 5 & 0.34 & -0.20^{\mathrm{NS}} \\ 6 & 0.33 & -0.05^{\mathrm{NS}} \\ 7 & 0.36 & 0.23^{\mathrm{NS}} \\ 8 & 0.36 & 0.35^{* *} \\ 9 & 0.38 & 0.38^{* *} \\ 10 & 0.58 & 0.41^{* *} \\ & & \\ & \text { NS }=P>0.05 & \\ * & =P=0.05-0.01 \\ * * & =P=0.01-0.001 \\ * * * & =P<0.001\end{array}$

estimated the quadratic regression coefficient from the first 4, 5, 6, 7, 8 and 9 weeks of growth in the field to see how early in the season we can obtain estimates which have as high a correlation with environmental sensitivity and as high a heritability as those obtained at 10 weeks. These correlations and heritabilities are listed in table 6 . It is clear from these estimates that at no time prior to the tenth height measurement can we obtain estimates of the quadratic coefficients which have as high a narrow heritability or as high a correlation with environmental sensitivity as those obtained after the tenth measurement. Nevertheless, the reduced efficiency of indirect selection that would result from using the lower correlations and heritabilities based on eight or nine weekly height measurements would be more than offset by removing the necessity for family selection and having to raise a second sample of each of the selected families for breeding purposes.

\section{REPEATABILITY OVER ENVIRONMENTS}

A major limitation encountered by Brumpton, Boughey and Jinks (1977) in selecting directly for environmental sensitivity was the low repeatability of the measure of sensitivity from one environment to another. The prospects of selecting for sensitivity indirectly depends, therefore, on the extent to which this limitation can be overcome. This has been investigated in two further samples of 18 of the D lines raised during 1977 in two contrasting environments as part of a larger experiment.

The $18 \mathrm{D}$ lines incorporated a stratified sample of 10 of the 60 available in respect of their final heights in 1976 and one representative of each of the four selections $(H h, H 1, L h, L 1)$ described by Jinks, Jayasekara and Boughey (1977). The experimental design was identical with that of the main 
experiment described in Section 2. They were raised, however, in two environments on the Avoncroft site at planting densities which were one third higher and one third lower, respectively, and sown 15 days later than the main experiment. Thus these two environments differed from the main experiment in location, planting density and sowing date, and from one another in planting density. The three environments differ, therefore, for the environmental variables used to determine the environmental sensitivities of the D lines (see table 1). In 1977 we have, therefore, eight individually randomised plants of each of $18 \mathrm{D}$ lines raised in each of three environments

TABLE 7

Rank correlations of the quadratic regression coefficients over lines for each of the three pairs of environments

$\begin{array}{ccc}\begin{array}{l}\text { Environments } \\ \text { Avoncroft }\end{array} & \text { Edgbaston } & \begin{array}{c}\text { Avoncroft } \\ \text { low density }\end{array} \\ \text { low density } & 0.90 * * * & - \\ \text { high density } & 0.90 * * * & 0.91 * * * * \\ & * * * P<0.001 & \end{array}$

and eight successive height measurements made at weekly intervals for all 432 plants. Since, however, the common data do not extend to the final height measurement, we can compare one of our indirect measures of sensitivity (the quadratic coefficient of the growth curve) but not the other (the proportion of the final height achieved by the sixth week) over the three environments.

Weighted least squares estimates of the quadratic regression coefficients of the cubic growth curves were obtained for each line in each environment as described in Section 3. Rank correlations of these estimates over lines for each pair of environments are given in table 7. All three correlations are very high and highly significant. Over the kinds of environments in which we have conducted our investigations of environmental sensitivity, therefore, the relative estimates of the quadratic coefficients over lines have a high repeatability. Hence we can rank our lines for this property in one environment with a high probability that this ranking will apply equally well in another environment.

\section{Conclusions}

Our results leave no doubt that pattern of growth, as summarised either by the quadratic component of essentially cubic growth curves or by the proportion of the final height achieved by the middle of the growing season (R5), is a determinant of the environmental sensitivity for final height, variation in final height being the single most important component of the total phenotypic variation in our Nicotiana rustica material. Thus the earlier after sowing a plant achieves its maximum growth rate the lower its sensitivity to such environmental variables as sowing date, and planting density irrespective of its final height.

The heritabilities of the quadratic component and R5 are at the higher end of the range observed in this material and the repeatability of the 
quadratic component over diverse environments is exceptionally high. Indirect selection for environmental sensitivity by selecting for the quadratic component is, therefore, an attractive possibility in that it simultaneously overcomes many of the technical problems and limitations encountered during direct selection.

Acknowledgment.-We are indebted to $\mathrm{Mr} \mathrm{P}$. W. Greene for assisting with the scoring of the experiments at Avoncroft.

\section{References}

BOUGHEY, HILARIE, AND JINKs, J. L. 1978. Joint selection for both extremes of mean performance and of sensitivity to a macro-environmental variable. III. The determinants of sensitivity. Heredity, 40, 363-369.

BRUMPTON, R. J., BOUGHEY, HILARIE, AND JINks, J. L. 1977. Joint selection for both extremes of mean performance and of sensitivity to a macro-environmental variable. I. Family selection. Heredity, 38, 219-226.

jINKS, J. L., JAYASEKARA, N. E. M., AND Bovghey, HILARIE. 1977 . Joint selection for both extremes of mean performance and of sensitivity to a macro-environmental variable. II. Single seed descent. Heredity, 39, 345-355.

MATHER, K., AND Jinks, J. L. 1971. Biometrical Genetics. London: Chapman and Hall.

PERKINS, J. M. 1974. Orthogonal and principal components analysis of genotypeenvironmental interactions for multiple metrical traits. Heredity, 32, 189-209.

PERKINS, J. M., AND JiNKS, J. L. 1968. Environmental and genotype-environmental components of variability. IV. Non-linear interactions for multiple inbred lines. Heredity, $23,525-536$. 